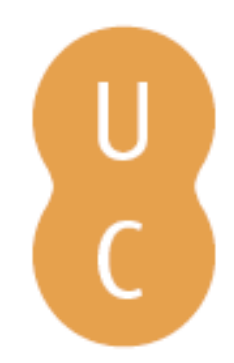

\title{
nombalina
}

\section{Entre textões e escritões: a narrativa projetada}

\author{
Autor(es): $\quad$ Maduro, Daniela
}

Publicado por: Imprensa da Universidade de Coimbra

URL

persistente: URI:http://hdl.handle.net/10316.2/41354

DOI: $\quad$ DOI:https://doi.org/10.14195/978-989-26-1324-6_13

Accessed : $\quad$ 26-Apr-2023 11:59:09

A navegação consulta e descarregamento dos títulos inseridos nas Bibliotecas Digitais UC Digitalis, UC Pombalina e UC Impactum, pressupõem a aceitação plena e sem reservas dos Termos e Condições de Uso destas Bibliotecas Digitais, disponíveis em https://digitalis.uc.pt/pt-pt/termos.

Conforme exposto nos referidos Termos e Condições de Uso, o descarregamento de títulos de acesso restrito requer uma licença válida de autorização devendo o utilizador aceder ao(s) documento(s) a partir de um endereço de IP da instituição detentora da supramencionada licença.

Ao utilizador é apenas permitido o descarregamento para uso pessoal, pelo que o emprego do(s) título(s) descarregado(s) para outro fim, designadamente comercial, carece de autorização do respetivo autor ou editor da obra.

Na medida em que todas as obras da UC Digitalis se encontram protegidas pelo Código do Direito de Autor e Direitos Conexos e demais legislação aplicável, toda a cópia, parcial ou total, deste documento, nos casos em que é legalmente admitida, deverá conter ou fazer-se acompanhar por este aviso.

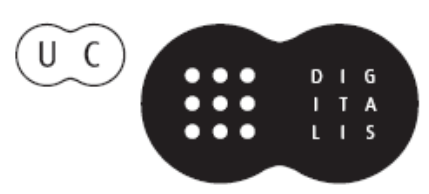





\section{ENTRE TEXTÕES E ESCRITÕES:}

\section{A NARRATIVA PROJETADA}

Daniela Maduro

Centro de Literatura Portuguesa / FLUC

\section{Os escrileitores}

A World Wide Web trouxe consigo inúmeras formas de publicação. Foi no meio digital que o autor veio a assumir a função de blogger ou de gestor de conteúdos. A sua presença é hoje constatada em várias plataformas onde os seus textos podem ser publicados instantaneamente. Para além disso, a junção entre a tecnologia móvel e os media sociais criou a possibilidade de conectividade permanente. A audiência encontra-se hoje à distância de um dígito.

Marie-Laure Ryan, em Avatars of Story (2006), referiu-se a uma abordagem prática à narrativa digital. Esta teria em conta "a importância das histórias na vida das pessoas" (RYAN, 2006: xiii) e veria a World Wide Web como um veículo para a transmissão de narrativas, quer estas fossem publicadas em blogs, em chatrooms ou até num anúncio publicitário. É neste contexto que surge o termo wreader, o leitor que também assume funções de escritor. Esta palavra refere-se hoje à comunidade que lê e publica textos através dos 
seus ecrãs mas, na literatura eletrónica ${ }^{133}$, o termo wreader $^{134}$ viria a representar um leitor livre da hegemonia autoral. Em meados dos anos noventa, Pedro Barbosa, pioneiro em Portugal na produção de literatura combinatória através do computador, referia-se igualmente à existência de um escrileitor "que pratica a leitura pela escrita e a escrita pela leitura numa nova simbiose interactiva" (Barbosa, 1996: 11). Pedro Barbosa criou o programa de geração automática de textos intitulado Sintext, juntamente com Abílio Cavalheiro ${ }^{135}$. De acordo com Barbosa, este programa permitiria criar o seguinte tipo de texto: "o texto surge aqui como uma estrutura geradora de sentidos, ou como texto em processo, e não como meio de comunicação intersubjectiva entre autor e fruidor" (Barbosa, 1996: 11.). O texto surgiria, assim, não como um produto finalizado gerado por um autor, mas como uma matriz de significados.

Para além de reunirem pessoas com interesses em comum, os media sociais estão a ser utilizados para criação artística e literária ${ }^{136}$. A plataforma Facebook, por exemplo, permite a publicação de breves comentários sobre o quotidiano ou partilha instantânea de notícias ou curiosidades, mas também terá motivado a criação de diferentes formas literárias. Um exemplo disso são os microcontos (também intitulados minicontos ou nanocontos) constituídos por uma ou duas linhas, através das quais os leitores partilham pequenas histórias.

\footnotetext{
${ }^{133}$ Esta é uma área em franca expansão e, dada a sua hibridez e dependência da tecnologia - o que permite a criação de novos tipos de textos, mas destina outros à obsolescência -, tornar-se difícil defini-la com precisão. N. Katherine Hayles sugeriu a seguinte definição de literatura eletrónica: "Electronic literature, generally considered to exclude print literature that has been digitized, is by contrast 'digital born', a first-generation digital object created on a computer and (usually) meant to be read on a computer" (Hayles, 2008: 3). ${ }^{134}$ George Landow usou este termo no texto "What's a critic to do? Critical theory in the age of hypertext" (1994) (Schäfer, 2007: 144)

${ }_{135}$ Mais tarde, Barbosa viria a colaborar com José Manuel Torres para criar uma versão web deste programa, o Sintext-Web (2000). Seis poemas criados por Barbosa e organizados por Rui Torres foram publicados no terceiro volume da ELO Collection sob o título Ciberliterature. Estes podem ser lidos em: http://collection.eliterature. org/3/work.html?work=cyberliterature.

${ }^{136}$ Joseph Tabbi refere-se a blogs como "objetos de conhecimento" (Tabbi, 2010: 4).
} 
A página Flash-Fiction ${ }^{137}$, por exemplo, declara que o seu propósito é oferecer aos escritores uma frase inicial de onde poderão partir as suas histórias. A página portuguesa Micro $\operatorname{Contos}^{138}$ tem mais de 24.000 subscritores e descreve-se como um "contador de pequenas histórias". As pequenas narrativas introduzidas pelos escrileitores vêm normalmente acompanhadas de fotografias. Após a inserção de um texto sob a forma de comentário, os leitores podem responder, partilhar ou atribuir um "like", interagindo assim com o autor.

No volume II da Electronic Literature Collection, disponível online, é possível encontrar uma obra que também utiliza a plataforma Facebook como ferramenta criativa. The Fugue Book (2008) usa a informação pessoal contida nesta página, bem como o e-mail do leitor, para criar uma narrativa acerca de questões de privacidade e identidade. A caixa de correio do leitor começa por ser invadida por e-mails de diferentes personagens. Enquanto o leitor lê a obra, é recolhida informação pessoal dos seus amigos na plataforma do Facebook. O conjunto de dados reunido permite que as personagens ajam como se mantivessem uma relação de amizade com este. The Fugue Book é um exercício irónico sobre questões de identidade, que usa plataformas como wikis, fóruns, histórias eróticas, blogs e outros media sociais para formular uma narrativa. De acordo com o autor, o leitor poderá fugir de tudo, mas não poderá fugir de si próprio: "The Fugue fa participar els teus amics en la ficció. Els teus amics no es comportaran igual que ho fan a The Fugue (o potser

\footnotetext{
${ }^{137}$ A página em questão pode ser consultada em: https:/www.facebook.com/pages/ Flash-Fiction-Chronicles/111807932198001?fref=ts. Existe uma outra página onde é explicada a origem do termo: https://www.facebook.com/pages/Flash=-fiction107726225923884/?frefts\&rf=177360282408549\#.

${ }^{138}$ A página pode ser consultada em: https://www.facebook.com/microcontos. Recentemente foi publicado um livro com o conteúdo desta página, o que comprova que o formato impresso e formato digital, frequentemente considerados como oponentes, podem, na verdade, coexistir e persistir.
} 
sí, encara que no t'ho sembli). Si vols, podràs fugir d'ells. Fins i tot podràs fugir de The Fugue, però no podràs fugir de tu mateix"139.

Para além do Facebook, existem outras plataformas que possibilitam a publicação instantânea de um texto. Muitos dos processos de escrita adotados recordam práticas literárias e artísticas criadas antes da emergência do computador. Estes denunciam igualmente que o desejo de intensificar o papel participativo do leitor é uma tendência que antecede a adoção do computador enquanto recurso para criação literária. Bryan Alexander, num livro dedicado à "digital storytelling", referiu-se às Wikis como um instrumento de escrita colaborativa e defendeu que estas podem assumir a forma do jogo surrealista "cadáver esquisito". Este é o processo de composição usado para produzir o romance exquisite_code (2010). Durante cinco dias, um grupo de escritores sentou-se a uma mesa para escrever ao longo de oito horas. Uma audiência assistia à escrita deste romance. Este detalhe torna esta atividade numa performance, bem como anula a fixidez associada à escrita. exquisite_code contraria a noção de escrita e leitura como atividades solitárias. Segundo Mark Marino, "exquisite_code rompe com a noção romântica de um texto criado por um único autor" (Marino, 2013: 285).

Ao longo da escrita do romance exquisite_code (2010), existe um narrador $\left(\right.$ proctor $^{140}$ ) que lê em voz alta o resultado da experiência. Esta é descrita da seguinte forma:

Reading the text, then, becomes a game of trying to detect the signatures of the particular collaborators in the mash,

\footnotetext{
139 "The Fugue faz com que os teus amigos participem na ficção. Os teus amigos podem não se comportar como o fazem no The Fugue (ou talvez possa assim parecer). Se tu quiseres, podes evitá-los. Tu podes até escapar do The Fugue, mas não podes escapar de ti mesmo".

${ }^{140}$ Este é também aquele que determina que método de programação deve ser seguido pelos escritores. Para além de funcionar como um sistema autoral, Marino refere que este é uma metonímia do código usado para construir exquisit_code.
} 
as evidenced by repeating themes, diction, and punctuation, as well as deducing the process, how each passage grew out of the dynamics of the group and the randomly selected prompts. (Marino, 2013: 285).

Sendo assim, a leitura desta obra não se encontra dependente da coerência ou linearidade do texto, mas do rastreamento de detalhes significativos produzidos ao longo do processo de escrita colaborativa. A obra é constituída pela cadeia de código de Markov, uma adaptação algorítmica dos cut ups de William Burroughs e SMS. Este romance pode ainda ser impresso on demand. Na sua versão impressa, vêm incluídas as linhas de código que foram produzidas durante a performance de exquisite_code. Para além de ler o resultado da experiência, o leitor é também convidado a interpretar o código. Toda a performance foi filmada, pelo que o leitor poderá ainda visualizar todo o processo de construção de exquisite_code. Sendo assim, esta obra reúne diversas formas de representação e transforma o ato de contar histórias numa experiência híbrida, tecida por várias mãos.

O podcast é outra das formas de narrar uma história descrita por Alexander. Para este autor, esta forma de publicação reúne vários tipos de media (ou práticas de storytelling):

Listening to a voice or voices tell a story (...) is an ancient human experience, hearkening back to the oral tradition. (...) the podcaster's voice resembles other speaking voices familiar to audiences of different ages and media experience: the radio announcer, the newsreel narrator, the TV anchor, even the ham radio operator. Further, we may also know that telling voice from audiobooks (formerly "books on tape"). We already knew aural performance before downloading the first mp3 into RSS or iTunes. In this way, podcasts are deeply historical, even nostalgic. (Alexander, 2011: 77) 
A categoria Web Video centra-se na imagem em movimento e é resumida por Alexander aos vídeos publicados no YouTube. Nesta plataforma, o autor pode manter um canal próprio e construir um reportório. Pode ainda entrar em contacto com a audiência através do painel de comentários. Comum a todas estas formas de publicação ou práticas de storytelling é o facto de não existir o editor como intermediário entre o leitor e o autor. A aproximação entre ambos faz com que - tal como é sugerido por Alexander no excerto acima citado - o autor se assemelhe ao contador de histórias da tradição oral. Em ambiente digital, a comunicação pode tornar-se bidirecional. Adicionalmente, leitor e autor podem trocar de papéis entre si.

Bryan Alexander afirma que a "digital storytelling" terá surgido com as primeiras experiências com o computador. Segundo o mesmo autor, a história desta prática poderá ter começado de duas formas:

(...) we could begin with a game called Spacewar, an early storytelling engine that dates back to the 1960s. If we think of world-building as storytelling, the first virtual worlds in the early internet age - all text based! — appeared in the late 1970s, with the first MUDs (Multi-User Dimensions or Multi-User Dungeons)" (Alexander, 2011: 17).

De acordo com Alexander, a atividade de contar histórias através do computador está relacionada com a emergência dos jogos de computador e mundos virtuais. No final dos anos oitenta, Roy Ascott sublinhava a chegada de uma nova ordem na arte, a ordem da interatividade e da 'autoria dispersa'. Anunciava igualmente a emergência de um novo cânone: o "cânone do imaterial e participatório" (Ascott, 2002: 339). A telematics seria um conjunto de comunicações estabelecidas entre utilizadores ou instituições dispersas, através do computador. Ascott considerava que esta envolvia a interação entre seres humanos e "entre a mente humana e sistemas artificiais 
de inteligência e perceção" (2002: 334). Na sua descrição de telemática, Ascott mencionava a existência de uma "síntese entre artes" em ambientes interativos. Referia-se igualmente a uma obra de arte total constituída por dados ou uma Gesamtdatenwerk que transformava o observador em participante. Na Gesamtdatenwerk, cabia ao utilizador negociar o significado, o que fazia com que a criatividade residisse, não só no trabalho do artista, mas também na perceção da obra de arte. O "significado" seria assim transformado no produto da interação entre obra e observador. Por este motivo, estaria "num fluxo constante, de mudança e transformação interminável" (2002: 336). Na relação de "simbiose entre humano e máquina" a perceção humana seria para Ascott o produto de negociação. Porque estavam interligados através da rede, os utilizadores tornavam-se em participantes numa "acupunctura global" que constrói "um fluxo de data mundial" (2002: 342). Ascott referia-se a uma arte à escala planetária formada através de um "telematic embrace" (2002: 344). A adoção do computador teria, assim, como objetivo conferir ao leitor um papel mais dinâmico e pertinente na receção ou produção da obra de arte.

Walter Benjamin havia referido, no seu texto sobre a obra de arte na época da sua possibilidade de reprodução técnica, que o leitor pretendia tornar-se em autor (Benjamin, 2003: 29). Benjamin referia-se a artigos de opinião publicados em jornais. Desde as suas primeiras manifestações, a literatura eletrónica tem vindo a ampliar as funções do leitor. A impressão que estas surgem intensificadas perante um computador é produzida pelas características intrínsecas do meio - tais como o célere processamento de informação e a lata capacidade de armazenamento de dados - que cooperam entre si para surpreender o leitor com um vasto número de respostas textuais. Porém, como demonstrarei, um texto digital interativo não se resume à capacidade de oferecer ao leitor um maior poder de intervenção. A interatividade não deve ser representada por um conjunto de tarefas oferecidas ao "escrileitor", nem pela oportunidade de participar na 
construção do texto. Neste artigo, esta será descrita como um elemento expressivo e figurativo manifestado por textos que apresentam uma dinâmica particular.

\section{Ergodicidade e narratividade}

Em 2001, Rita Raley descrevia o funcionamento do hipertexto da seguinte forma: "hypertext works by connection, assemblage, and combination - by connecting content blocks, phrases, phrase regimes, nodes, computers, programs, and lines of code. It is not about signification but mapping: not ordering, tracing, and fixing, but transmission, relay, and movement" (Raley, 2001). O hipertexto seria um texto dividido em lexias interligadas de forma associativa e acedidas aleatoriamente. Já as hiperficções eletrónicas nasciam do aproveitamento dos recursos tecnológicos para concretizar o texto em aberto, fragmentado, rizomático e livre de uma sequência pré-determinada pelo autor. Estas características seriam catalisadas pelo recurso à intervenção do leitor na montagem do texto ${ }^{141}$. Segundo Alice Bell, os primeiros teóricos dedicados ao estudo e produção de ficções hipertextuais reconheciam que a multilinearidade poderia provocar "confusão e desorientação", mas que estas poderiam ser contornadas se o leitor continuasse a ler "até que as suas curiosidades pessoais" fossem satisfeitas (Bell, 2009: 14). Bell refere que, na segunda fase da ficção hipertextual, a questão da multilinearidade e da incoerência ao nível estrutural é revista da seguinte forma: "the structure of the text, and the reader's role within it, represent a means of prohibiting her or him from fully engaging with the

\footnotetext{
${ }^{141}$ Alice Bell refere que esta seria uma falácia mantida na fase inicial da ficção hipertextual: "Overall, while hypertext fiction does offer choice, the reader's degree of control, which was envisaged by many first-wave theorists, is inflated and readers are erroneously attributed with unrealistic powers in their actual capacity to manipulate and operate within the text" (Bell, 2009: 12).
} 
narratives that hypertext novels contain" (2009: 15). Sendo assim, a tónica seria colocada na resistência exercida pelo texto, e não no grau de liberdade, escolha ou participação oferecida ao leitor. Porém, a possibilidade de interatividade - um termo problemático, mas que continua a permear textos teóricos ${ }^{142}$ - e a multilinearidade permaneceram como características fundamentais da literatura eletrónica.

Para além da abordagem prática acima descrita, Marie-Laure Ryan referiu-se igualmente à abordagem expansionista. Esta abordagem vê a narrativa como um conceito mutável, que difere de cultura para cultura e que evolui de acordo com as inovações tecnológicas (Ryan, 2006: xv). Já a abordagem metafórica procura inspiração em conceitos da narratologia para desenhar e promover aplicações que não são originalmente criadas para contar histórias (2006: xiv). Este é o caso de inúmeras narrativas criadas dentro da literatura eletrónica. No entanto, alguns textos produzidos através do computador, dado o seu carácter experimental, interativo ou híbrido, tornam difícil a sua categorização como textos literários ou, mais concretamente, narrativos. Reis referiu-se a "textos narrativos" situados em "vários contextos comunicativos", que recorrem "a diferentes suportes expressivos" e que "apontam para a possibilidade de se estudar a narratividade como processo geral que é comum a todas as narrativas e não apenas exclusivo das literárias" (Reis, 1997: 344). De facto, uma narrativa pode estender-se a várias formas de representação e pode assumir vários perfis. A possibilidade de existência de vários tipos de narrativa exige uma abordagem expansionista.

Markku Eskelinen afirmou que existem textos ergódicos (ou cibertextos) cuja abordagem é permanentemente adiada pelos estudos literários, por ausência de instrumentos de análise adequados.

\footnotetext{
${ }^{142}$ Este termo tem vindo a ser considerado como demasiado abrangente e, por este motivo, improfícuo enquanto conceito teórico (Aarseth, Eskelinen). Embora Aarseth tenha rejeitado este termo, o conceito "interatividade" será aqui utilizado como distinto, mas inseparável, do fenómeno de ergodicidade identificado por este autor.
} 
O adjetivo "ergódico" foi sugerido por Espen Aarseth para descrever todos os textos (impressos ou digitais) que exijam do leitor um "esforço não-trivial" para percorrer o texto (Aarseth, 1997: 1). Isto significa que o leitor tem de levar a cabo um conjunto de escolhas para completar uma sessão de leitura. Todavia, segundo Eskelinen, o conjunto de escolhas formulado pelo leitor institui um conflito entre camadas ergódicas e narrativas. A teoria do cibertexto vê um texto como uma máquina concreta de produção e consumo de sinais e o medium como operador dessa cadeia de sinais. Esta cadeia divide-se entre textões (cadeia de sinais que compõem o texto) e escritões (cadeia de sinais, tal como são apresentados ao leitor/utilizador). Dada a sua volatilidade, os textos ergódicos inviabilizam uma abordagem de uma narrativa baseada na sucessão de eventos ou na existência de um narrador. Eskelinen acredita que a componente ergódica e a componente narrativa podem surgir como conciliadas: "We already know that the ergodic side can coexist and be combined with traditional text types (argument, description and narrative)" (Eskelinen, 2012: 88). Porém, a conceção de texto como um todo inabalável e a ideia de narrativa como uma sequência lógica de eventos continuam a representar um obstáculo para a definição destes objetos textuais como literários.

Ryan referiu-se ao texto eletrónico como uma "massa indefinida" e não como um objeto discreto e por isso defende que "não é necessário ler a totalidade do texto" (Ryan, 2001: 47). Os textos aqui apresentados podem ser definidos como uma "massa indefinida" que, no entanto, apresentam características literárias e elementos narrativos ${ }^{143}$. Eles efetuam um aproveitamento expressivo do meio,

\footnotetext{
${ }^{143} \mathrm{Em}$ todos os textos pertencentes à literatura eletrónica é possível rastrear categorias e procedimentos desenvolvidos dentro da literatura. Porém, a literatura eletrónica também faz uso de recursos expressivos produzidos dentro das artes visuais, performativas ou jogos de computador. A hibridez manifestada por muitas obras de literatura eletrónica, onde a primazia não é dada à palavra, impede a sua definição como parte da literatura, porque esta encontra-se profundamente ligada ao texto verbal.
} 
veiculam mensagens e catalisam a emergência de significado(s). Eles não são um leque de oportunidades de interação, mas um vasto território onde o significado prospera e desafios teóricos surgem a todo o momento.

No caso dos textos interativos, é normalmente definido que a quantidade de tarefas propostas ao leitor interrompe a perceção de uma narrativa. Porém, para Ryan, isto não significa que a narratologia deva ser abandonada:

I regard narratology as an unfinished project, and if classical narratology fails the test of interactive textuality, this does not necessarily mean that interactive textuality fails the test of narrativity. It rather means that narratology must expand beyond its original territory. (...) the development of a digital narratology will be a long-term collaborative project, and I can only sketch here what I consider to be its most urgent concerns. (Ryan, 2006: 98)

O aparecimento de novos tipos de textos ${ }^{144}$ força os limites do conceito de literatura. Face à emergência destes textos ou de novas tecnologias de escrita e leitura, Eskelinen constata, tal como Ryan, que existe a necessidade de expandir a ação da narratologia. Carlos Reis referiu-se ao campo literário como um "vasto domínio de fronteiras algo fluídas" (Reis, 1997: 21). Os conceitos criados dentro dos estudos literários estão em permanente mutação. A definição de narrativa não se encontra circunscrita. Como frisarei nas próximas linhas, este é

\footnotetext{
${ }^{144}$ Scott Rettberg identificou os seguintes (novos) textos na área da literatura eletrónica: "hypertext fiction (both early works published on CD and published on the Web), literary text installations and CAVE works, ludic works that involve the conventions of games, kinetic poetry, interactive fiction, interactive drama, email narrative, visual poetry and works that reference the concrete poetry tradition, works that harvest and integrate texts from the web, poetry generators, a locative narrative, and works that emphasize aspects of user interaction" (Rettberg, 2013: 25).
} 
um conceito flexível, que pode ser adaptado a diferentes contextos e tipos de texto, e não apenas a uma sequência coerente de eventos narrados que culminam num desfecho.

\section{Significado emergente}

O funcionamento do computador tem um impacto na forma como os textos são apresentados ao leitor. O meio, ou o formato em que o texto é apresentado, não surge apenas como um suporte que canaliza a informação, mas como um elemento que contribui decisivamente para a formulação de significado. Segundo Wolfgang Iser, os textos ficcionais têm uma "conectividade" que é interrompida por espaços em branco. Estes são preenchidos pelo leitor através de "decisões seletivas" e correspondem a inúmeras possibilidades de sentido (Iser, 1994: 286). É através do estabelecimento de associações, ou "alien associations" (Pater, 1994 apud Iser: 206), e da exploração da possibilidade de sentido que o leitor compreende um texto. Num texto digital ou num cibertexto, o leitor tem de lidar com a imprevisibilidade dos textões. Estes são invocados por si, mas o leitor não chega a conhecer esta cadeia de sinais. Quando surgem no ecrã, os textões já foram transformados em escritões. Esta característica mantém um texto digital num estado permanentemente potencial.

Segundo Zumthor, os espaços em branco "constituem um espaço de liberdade ilusório" que apenas pode ser ocupado temporalmente. Para Zumthor, o sentido tem uma "existência transitória e ficcional" (Zumthor, 2007: 54). Para além disso, cada leitor pode "concretizar" o mundo ficcional de diferentes formas. Ryan identificou a hipótese de existir um texto diferente para cada leitor: "filling in of gaps and places of indeterminacy that can take a highly personal form, since every reader completes the text on the basis of a different life experience and internalized knowledge" (Ryan, 2001: 44). A mesma 
autora, associando-se a David Lewis, sugeriu a possibilidade de existência de "uma pluralidade de mundos textuais" (Ryan, 2001: 44). Philippe Bootz defende que um texto eletrónico pode dividir-se em dois: o texte-auteur e texte-à-voir. O primeiro apenas está ao alcance do autor, enquanto o segundo tipo de texto permanece virtual. Já o texte-à-voir é apenas visível para o leitor, mas o texte-auteur (ou a intenção do autor) permanece oculto (Bootz, 2006: 4). Segundo Bootz, existe uma "cesura semiótica" entre ambos: "There exists, then, a "semiotic gap" (...) which comes out from the loss of visibility of the intention of the author. The "texte-à-voir" reveals an intentionality that is its own and adapted and that may differ greatly from that of the 'texte-auteur'." (2006: 4). Esta descrição apresentada por Bootz permite constatar que o texto a que o leitor tem acesso pode ser distinto daquele criado pelo autor ${ }^{145}$.

Ryan salienta que, para Lévi, o virtual como potencial "não só representa o modo de existir do texto literário, mas também o estado ontológico de todas as formas de textualidade” (Ryan, 2001: 45). Após ser escrito, o texto permanece num estado virtual até ser despertado pelo leitor. Ele não é concretizado apenas através da interpretação, mas também por intermédio de uma simulação efetuada pelo leitor, através da imaginação:

In the case of texts, the process of actualization involves not only the process of "filling in the blanks" described by Iser but also simulating in imagination the depicted scenes, characters, and events, and spatializing the text by following the threads of various thematic webs, often against the directionality of the linear sequence. (Ryan, 2001: 45)

\footnotetext{
${ }^{145}$ Tal como Bootz, Ryan considera que existe um texto "como uma coleção de sinais escritos pelo autor" e o "texto construído mentalmente pelo leitor". Porém, entre ambos, existe um outro texto: o texto presente no ecrã (Ryan, 2001: 46).
} 
Para Ryan o texto já é um espaço virtual, mas a tecnologia eletrónica deixa entrever uma nova faceta: "the marriage of postmodernism and electronic technology, by producing the freely navigable networks of hypertext, has elevated this built-in virtuality to a higher power" (2001: 45-46). Citando Lévi, Ryan refere que o hipertexto é uma "matriz de textos potenciais". De facto, a estrutura hipertextual transmite a impressão de um texto gerado a todo o momento, que pode ser percorrido infinitamente. Tendo em conta que a literatura eletrónica dispõe de uma base de dados e da velocidade de processamento do computador, essa impressão poderá ser largamente intensificada.

The Jew's Daughter (2000-2006) de Judd Morrissey é uma narrativa recombinante cujo texto surge apresentado numa página em branco. À medida que o leitor coloca o cursor sobre a mancha gráfica, descobre que existem palavras que desaparecem e dão lugar a outras. O texto reformula-se indefinidamente, oferecendo novas possibilidades de significação. Contudo, nem todos os textos digitais apresentam uma possibilidade generativa como aquela manifestada por esta obra. De facto, ainda que expressem o contrário (isto é, ainda que se apresentem como infinitos), estes são estruturalmente finitos, justamente porque partem de uma base de dados com um número limitado de elementos ${ }^{146}$. A imaginação, coadjuvada pelo ato interpretativo, poderá expandir o potencial de um texto, tecendo associações improváveis durante a leitura ${ }^{147}$, ou posteriormente, através de apropriações ou

\footnotetext{
${ }^{146}$ Existem obras que partem, não de uma base de dados, mas, por exemplo, de informação recolhida online. Estas obras, embora possam alterar-se a cada visita, estão também cingidas ao programado pelos seus autores. A título de exemplo, a obra poética The Deletionist (2013), criada por Amaranth Borsuk, Jesper Juul e Nick Montfort, reduz páginas visitadas a um conjunto de palavras-chave para gerar um novo poema. Embora as palavras sejam substituídas por outras a cada visita, a estrutura e comportamento desta obra permanecem inalterados.

${ }^{147}$ No entanto, durante o contacto com o texto, este permanece restrito à sua arquitetura, a qual é pré-determinada e circunscrita ao tempo reservado para lê-lo ou ao número de elementos que podem ser configurados ou explorados. Neste sentido, o ato de abandonar o texto é a única decisão ou poder verdadeiramente oferecido ao leitor.
} 
releituras do mesmo. John Gibson identificou uma colaboração entre leitor e autor executada através da imaginação:

Literary works generate (...) the fictional worlds they inhabit in tandem with the reader, by presenting their language as in effect a recipe for the imagination. It is through this that a text that would otherwise remain a continuous string of empty representations is given substance. (Gibson, 2007: 131)

Para além de um esforço ergódico ou não-trivial, já aqui descrito, gostaria de chamar a atenção para a existência de um esforço imaginativo que se encontra dependente da suspensão de descrença para reconstruir um evento ou situação através da imaginação, que permite ao leitor encarnar (ou manter contacto com) personagens e especular acerca de uma possibilidade. Este permite igualmente manter o contacto com o mundo ficcional. O esforço imaginativo está ainda ligado à interpretação ${ }^{148}$ e impede que o texto interativo se torne num centro de operações executadas pelo leitor.

Segundo Hayles a literatura eletrónica surge da incapacidade de o computador lidar com a ambiguidade e plurissignificação (o código binário apenas permite a decisão entre 0 e 1). A "impiedade do código" é descrita por Hayles:

\begin{abstract}
Every voltage change must have a precise meaning in order to affect the behavior of the machine; without signifieds, code would have no efficacy. (...) every change in voltage must be given an unambiguous interpretation, or the program is likely not to function as intended. (...) Whatever messages on screen may say or imply, they are themselves generated
\end{abstract}

\footnotetext{
${ }^{148}$ A interpretação pode ser funcional e prática, ou seja, pode ser aplicada para interpretar o resultado de ações e melhorar a estratégia do leitor. Pode ainda focar-se nas estratégias figurativas do texto.
} 
through a machine dynamics that has little tolerance for ambiguity, floating signifiers, or signifiers without corresponding signifieds. (Hayles, 2005: 47)

Num texto digital, é a partir do código binário que o texto e a narrativa conquistam a sua plurissignificação. Entre o processador e o ecrã do computador é executada uma transformação: o código binário é transformado em imagens e palavras ou em código literário. Sendo assim, a ambiguidade e a proliferação do significado dependem da precisão da máquina: "Flexibility and the resulting mobilization of narrative ambiguities at a high level depend upon rigidity and precision at a low level (...) it is precisely the ability to build up from this reductive base that enables high-level literariness to be achieved" (Hayles, 2005: 53). O texto eletrónico parte da rigidez semântica do código binário (que apenas permite uma interpretação ou um significado) para as inúmeras possibilidades de significação.

Hayles referiu que a literatura eletrónica é gerada por um jogo entre "sequências sintagmáticas virtuais" e a "base de dados paradigmática" (2005: 54). De acordo com Pedro Barbosa, o programa Sintext é baseado na interseção entre o eixo paradigmático e o eixo sintagmático da linguagem. O eixo paradigmático é formado por elementos lexicais ou "Variantes" que são substituídos, a todo o momento, ao longo do eixo sintagmático, isto é, ao longo de uma "sequência parentetizada" ou "Constantes" (Barbosa, 5: 2000) que asseguram a geração do texto. Face a um texto eletrónico, o ato interpretativo começa na decisão entre 0 e 1. Só que esta ambivalência, aparentemente lacónica, pode gerar inúmeras possibilidades: "while they [computers] have no capacity for semantic recognition, the humans interpreting their results might see interesting patterns" (Hayles, 2008, 51). Sendo assim, o significado reside no processador num estado embrionário, mas depende do ser humano para ser materializado. 
Num texto ergódico, para que o significado possa ser constatado, o leitor tem de assumir várias funções. Aarseth distinguiu quatro funções do utilizador que poderão ser úteis para descrever a relação entre leitor e texto. No presente artigo, a referência a essas funções não tem como objetivo descrever o comportamento textual ou determinar o que é permitido ao leitor executar, mas identificar os procedimentos levados a cabo pelo leitor para compreender o texto. Estes encontram-se dependentes do esforço imaginativo e do ato interpretativo ${ }^{149}$.

Para Aarseth, a função interpretativa é exigida por todos os textos. Aqui gostaria de acrescentar que esta função é simultaneamente originada e origina todas as ações do leitor, pelo que é fundamental para aceder e compreender um texto. Para Aarseth, ao assumir a função exploratória, o leitor tem de escolher entre vários trilhos. No entanto, como nem sempre a exploração de um texto é executada através de uma decisão entre trilhos, esta função pode ser adaptada a outras formas de explorar o texto, como por exemplo, ouvir atentamente um excerto de narração; conhecer os diferentes ambientes que constituem a obra e rastrear ou apreciar os seus elementos expressivos. Para Aarseth, a função configurativa está relacionada com a escolha parcial ou criação de escritões. Já a função textónica surge associada à adição de textões de forma permanente. Como a criação de textões não se encontra ao alcance do leitor, pois estes terão sido pré-determinados, a função configurativa é aqui associada à forma como o leitor dispõe e organiza a informação de forma a proceder à leitura e interpretação de partes ou de todo o texto.

\footnotetext{
${ }^{149}$ A primazia oferecida à interpretação, a qual foi muitas vezes associada à tentativa de reduzir um texto a uma explicação inabalável, tem vindo a ser intensamente debatida. Gumbrecht referiu-se à intenção de o desconstrucionismo acabar com a "era do signo" (Gumbrecht, 2004: 53) e à tentativa de "destronar" a interpretação (5253). Aqui é defendido que o ato interpretativo, indelevelmente associado à tradição hermenêutica, não é uma forma de encontrar o significado uno de um texto, mas de multiplicar as suas possibilidades de significação. O ato interpretativo é igualmente visto como necessário para a compreensão de qualquer tipo de texto.
} 
O leitor age de acordo com a liberdade de escolha e de ação oferecida pelos criadores do texto e não pode colaborar na construção da obra, mas apenas reconstruí-la. Isto significa que a função textónica (que, segundo Aarseth implica adicionar "permanentemente" textões ao texto) teria de ser abandonada. Porém, os textões têm uma componente potencial e o leitor desconhece como eles emergem e que forma (ou significado) eles assumirão. Eles são catalisadores de mundos possíveis e a função textónica tem como objetivo encontrar a forma de despertar estes textões e desencadear esses mundos. O leitor leva a cabo um esforço imaginativo para especular sobre o que vem a seguir e para preencher espaços vazios. Para tal, o leitor tem de adotar a função textónica, ou seja, tem de criar e ajustar a sua estratégia para que os textões sejam transformados em escritões. Sendo assim, perante um texto interativo, dadas as funções assumidas pelo leitor, a emergência do significado depende de uma cooperação entre esforço ergódico e esforço imaginativo.

\section{Narrativas projetadas}

A obra La Disparue (2012) é um híbrido entre jogo e história policial que inclui o leitor como protagonista, ou melhor, como o detetive responsável por uma investigação. La Disparue é proposta como uma sequência de enigmas cuja resolução permite identificar o responsável pelo desaparecimento de Elisabeth Monohan e da morte de Kacey Harnois. Segundo Cécile Iran, Médéric Lulin e Sophie Séguin, os autores desta obra colaborativa, La Disparue é uma hiperficção. Esta história não está localizada apenas num sítio online, mas estende-se a diferentes espaços. Tal como é demonstrado ao longo da leitura de La Disparue, uma conta do Twitter ou do Facebook pode ajudar o leitor a obter mais informações para resolver o mistério. Um texto literário nem sempre corresponde à imagem de um romance ou a 
um texto publicado entre a capa e contracapa de um livro. Como sabemos, um texto literário pode assumir a forma de uma missiva ou de um fragmento (veja-se o caso do Livro do Desassossego). Para ler La Disparue, o leitor terá de reunir a informação dispersa por diversos locais, assumindo para isso a função exploratória e função configurativa. La Disparue pode ser definida como um processo que se estende a diferentes espaços em rede.

As histórias policiais em formato impresso são normalmente desenhadas para atingir um objetivo: alcançar o final da narrativa para descobrir a identidade ou localização do criminoso. Sendo assim, elas estão dependentes de uma estrutura aristotélica, ou seja, são construídas mediante uma lógica de início-meio-fim. La Disparue tem uma componente lúdica acentuada. Esta obra exige que o leitor vença vários desafios até ganhar o jogo ou descobrir a verdade, mas também é orientada para alcançar um desfecho (na verdade o leitor pode alcançar dois desfechos, conforme a sua performance). O desenrolar da narrativa depende da viagem exploratória executada pelo leitor.

O desejo de alcançar um desfecho está associado à sensação de concretização e de ordem restabelecida: espera-se que no final da história tudo seja revelado e que todas as questões do leitor sejam respondidas. Walter Ong considerou que as histórias policiais seriam um exemplo perfeito de estruturas baseadas na pirâmide de Gustav Freytag: "In the ideal detective story, ascending action builds relentlessly to all but unbearable tension, the climactic recognition and reversal releases the tension with explosive suddenness, and the dénouement disentangles everything totally" (Ong, 1982: 147). Schäfer e Gendolla referem que as histórias policiais inscritas no meio digital substituem a produção de suspense pelo desejo de superação de pequenos desafios (Schäfer e Gendolla, 2010: 97). Se o leitor/jogador não reunir as pistas deixadas pelos autores, não terá sucesso. Isto pode provocar uma espécie de tensão, tal como representada pela 
pirâmide de Freytag. Embora pareça que o leitor está envolvido na construção da narrativa (o leitor tem de visitar diversas páginas para recolher informação), a verdade é que o roteiro levado a cabo pelo leitor foi forjado pelos criadores de La Disparue. Poderá parecer que La Disparue é uma obra fragmentada, sem uma lógica interna, mas, na verdade, ela exibe uma estrutura episódica que corresponde às diferentes etapas da investigação/níveis do jogo. Apesar de propor várias tarefas situadas em diversos locais na rede, esta história policial manifesta uma coerência narrativa e não inviabiliza o alcance de um desfecho. Em La Disparue existe uma narrativa e uma lógica causal que é conhecida pelo leitor através da resolução de enigmas e superação de desafios.

O leitor de uma história policial impressa é igualmente um investigador porque coloca hipóteses e imagina cenários através das pistas deixadas pelo autor. Em La Disparue, o leitor é convidado a investir um esforço ergódico que o leva a explorar e configurar o texto até conhecer o paradeiro de uma das vítimas (ou alcançar a resolução do mistério). A história não é veiculada unicamente através de um texto verbal, mas também através de ficheiros, fotos, trilhos, provas ou pistas distribuídas por diversos locais. La Disparue é uma narrativa projetada porque o leitor terá de recolher diferentes elementos para conseguir uma versão aproximada desta.

Para conhecer os diferentes espaços de La Disparue (ou, para ler esta obra), o leitor terá de ativar uma função explorativa. Num momento inicial, o leitor é apresentado a uma secretária sobre a qual foram espalhados vários objetos. É através da exploração deste espaço, mas também através da sua configuração, que o leitor reúne algumas informações valiosas sobre si (a sua carteira e documentos pessoais pertencem à miscelânea de objetos dispostos sobre a mesa), acerca da aparência da vítima e do passo a dar em seguida. Para além do esforço ergódico investido pelo leitor, ele é também convidado a assumir um esforço imaginativo (afinal de contas, ele é 
o investigador responsável e a vida de Elisabeth Monohan depende da sua performance enquanto detetive, leitor e jogador). O leitor é encorajado a projetar diferentes cenários e a especular sobre o que terá acontecido.

Joseph Tabbi referiu-se à necessidade de pensar para além da "narrativa". Em vez desta, este autor mencionou a existência de "pistas" e "sugestões" (Tabbi, 2011: 3). Porém, a narrativa encontra-se enraizada no discurso dedicado à literatura eletrónica. Apesar de volátil e impreciso, este termo permeia consecutivamente o discurso sobre criação literária. Eskelinen afirmou que a ficção hipertextual, tal como alguma ficção pós-modernista, é potencialmente narrativa. Calleja referiu-se a uma narrativa experiencial, ou seja, uma narrativa que é formada na mente do leitor ao longo do jogo, através de "elementos representacionais e das nossas representações subjetivas" (Calleja, 2011: 119). Em vez de uma anti-narrativa ou de uma narrativa sabotada ou relutante, Aarseth referiu-se a afternoon: a story (1987-1990) ${ }^{150}$ como um "jogo de narração". Este autor considera que certos elementos da narrativa podem ser usados, mesmo sem a intenção de transmitir uma história ${ }^{151}$ (Aarseth, 1997: 94). Todos estes autores se referem a uma narrativa subentendida, eminente ou em formação que pode ser apresentada (ou suscitada) ao longo da leitura. Aqui pretendo sugerir a existência de uma narrativa projetada, que reside na memória do computador e que é despertada, quer através das funções assumidas pelo leitor, quer através de processos programados. Esta narrativa parece inexistente, mas é possível constatar vários vestígios da sua presença. A leitura desta narrativa torna-se assim num escrutínio dos seus elementos fundamentais que, quando reunidos, podem não produzir uma história, mas permanecer como meros alicerces do que seria uma narrativa.

\footnotetext{
${ }^{150}$ Esta obra é considerada por inúmeros autores como a primeira hiperficção eletrónica. ${ }^{151}$ Aarseth considera que as ações levadas a cabo durante um jogo não são narrativas nem constituem uma história, embora representem uma sucessão de eventos (Aarseth, 1997: 94).
} 
A condição provisória de uma narrativa projetada pode ser vislumbrada no jogo The Stanley Parable (2011-2013). Este é apresentado pelos seus criadores como uma "exploração de história, jogo e escolha”. Na página que dá acesso a este jogo, é colocado um desafio: "the story doesn't matter, it might not even be a game, and if you ever actually do have a choice, well let me know how you did it". Uma parábola é uma pequena narrativa que tem uma componente didática. De facto, o jogo parece recordar permanentemente ao leitor que o seu poder de escolha é ilusório. Neste jogo, o jogador é tratado como um peão que, tal como Stanley (o protagonista), tem de pressionar botões e obedecer a diretivas. $\mathrm{O}$ jogo exige que o leitor assuma constantemente uma função explorativa (este conhecerá inúmeros espaços e percorrerá diversos corredores em busca da história); uma função configurativa (premir botões e abrir portas são atividades constantemente exigidas) e uma função textónica (o leitor terá de tecer estratégias para alcançar o próximo nível ou ativar mais um trecho de narração).

No início do jogo, surge uma faixa onde é repetida a frase "The end is never the end". A parábola de Stanley é um jogo que faz uso da ironia para refletir sobre a própria estrutura e funcionamento. The Stanley Parable (que terá sido criado como uma ficção interativa e só depois assumiu a forma de um jogo) recorda as hiperficções multilineares e autorreflexivas do período clássico da literatura eletrónica. A sua estrutura episódica e multilinear assemelha-se ao texto identificado por Lev Manovich, o texto enquanto base de dados:

After the novel, and subsequently cinema privileged narrative as the key form of cultural expression of the modern age, the computer age introduces its correlate - database. Many new media objects do not tell stories; they don't have beginning or end; in fact, they don't have any development, thematically, formally or otherwise which would organize their elements 
into a sequence. Instead, they are collections of individual items, where every item has the same significance as any other. (Manovich, 2001: 8)

Esta parábola invoca um sentimento de estranheza porque a barreira entre jogo e narrativa autorreflexiva não é clara. A parábola de Stanley está ligada à literatura através de um constante desafio a alguns dos seus pressupostos. The Stanley Parable brinca com os limites da ficção e desafia a noção de lógica, coerência, verosimilhança e desfecho. A função interpretativa é constantemente invocada, não só porque o leitor se encontra perante um jogo e necessita de interpretar e avaliar o resultado das suas ações para melhorar ou estabelecer a sua estratégia, mas porque esta parábola está repleta de enigmas teóricos e referências literárias.

Stanley é um funcionário de uma empresa que um dia abandona o seu posto de trabalho para descobrir o motivo de uma falha técnica. Quando o faz, a aleatoriedade toma conta da sua vida. Assim que abandona o seu computador, descobre que o edifício onde trabalha foi evacuado. A missão de Stanley (e do jogador) é descobrir o que terá acontecido ou "a história”, o que resulta numa aventura metalética que mostra ao leitor elementos de uma narrativa, mas que boicota constantemente a formação de uma história. Stanley é apresentado por um narrador (Kevan Brighting) que o acompanha durante o percurso. Existe uma cena em que a voz do narrador descreve os sentimentos de Stanley (que é personificado pelo leitor) mas, a dado momento, a voz simula um estado de loucura e faz com que Stanley (ou o jogador) se atire de um prédio. O jogador é apresentado ao seu avatar que jaz inerte na rua. Enquanto isso, a voz centra-se numa outra personagem. Nesse momento, o narrador usa a expressão “This is a story about...". Porém, The Stanley Parable não é uma história sobre uma personagem. Ao assumir o papel de narrador, descrevendo os sentimentos e ações de Stanley ou contando a história da outra 
personagem, o sistema parece entrar em conflito. Reiniciar o jogo é a única solução encontrada pelo narrador.

A parábola de Stanley é constituída por um narrador, personagens e eventos (ou pelos mesmos elementos que constituem uma narrativa), mas a sua história não é conhecida. O esforço ergódico investido pelo jogador (ou a sua participação como personagem) não está na origem deste estado latente da narrativa. A formação de uma narrativa coerente já terá sido interrompida antes da intervenção do jogador, graças ao teor metaficcional assumido pelos autores desta parábola. The Stanley Parable não pretende transmitir uma história, mas uma ideia de narrativa ou um conjunto de características associadas a esta forma de representar eventos.

Para que o leitor não se perca, o narrador inclui, a dado momento, linhas amarelas ao longo dos corredores. Porém, o próprio narrador perde frequentemente o rumo da narrativa. As linhas desenhadas pelo narrador sobem paredes e percorrem o teto, o que resulta numa visão escheriana da estrutura da narrativa e da arquitetura do jogo. O narrador acaba por ter de pedir ao jogador para esquecer as linhas e para escrever a história (ou forjar o destino da personagem) e escolher um caminho diferente, "sem linhas, nem monitores”. O jogo apela à participação criativa do jogador. Para manter esta ilusão, o leitor tem de investir um esforço imaginativo. Sem reduzir a sua descrença - uma condição fundamental em textos interativos em que o leitor tem de assumir o papel de personagem - e sem compactuar com o narrador (ainda que este não seja fiável), o leitor não pode continuar em jogo. Nesta parábola, o narrador não é omnisciente e exibe algumas dificuldades em acompanhar o rumo da história. Isto acontece porque The Stanley Parable é uma narrativa projetada através do desafio das suas próprias fundações.

Os conflitos entre a escolha do leitor e as indicações do narrador são colmatados através do comportamento excêntrico deste. 
A voz da parábola de Stanley autointitula-se de narrador. Ela oferece indicações ao leitor como se fosse uma voz que emergisse de um romance. Em The Stanley Parable, uma estreita ligação com a literatura é concretizada a todo o momento. Na presente frase, o narrador recorre à terceira pessoa do singular: "Stanley escolheu a porta da esquerda". Porém, como é possível concluir durante o jogo, esta voz não corresponde à imagem de um narrador convencional ${ }^{152}$. Aarseth sublinhou que nos jogos de aventura ou de ficção existe um plano de negociação. Eskelinen frisou que, nos textos ergódicos, existe a presença de um "negociador", e não de um "narrador". (Aarseth, 2012 apud Eskelinen, 2012: 203). Segundo Aarseth, a intriga ergódica tem lugar num nível extraficcional e é direcionada contra o utilizador. Este, de acordo com Aarseth, "tem de descobrir por si próprio o que se está a passar". O utilizador implícito negoceia com uma voz ergódica ou um "correspondente simulado que relata os eventos ao utilizador". Segundo Eskelinen, a voz ergódica é um "negociador" e não um contador de histórias ou um narrador (Eskelinen, 2012: 204). A voz poderá fornecer informação, mas poderá também surgir como oponente do leitor. Eskelinen descreve a sua função da seguinte forma: "the voice's discontinuous narrations and descriptions serve by both distracting the user and giving him the information he needs to solve the puzzle" (2012: 204). A voz ergódica em The Stanley Parable surge como oponente ou como adjuvante, mas o puzzle fica por resolver. Em vez de uma história, esta parábola propõe uma aventura metaficcional.

Patricia Waugh definiu a metaficção como uma "escrita ficcional que auto-conscientemente e sistematicamente chama a atenção para a sua condição de artefacto, a fim de colocar questões sobre a

\footnotetext{
${ }^{152}$ De facto, o narrador poderá ser omnipresente, mas como é por vezes surpreendido pela audácia ou insolência do jogador, não é omnisciente. O narrador desta parábola é ainda bidiegético (Eskelinen), ou seja, pode alternar entre homodiegético e heterodiegético.
} 
relação entre ficção e realidade" (Waugh, 1996: 2). Sendo assim, a metaficção efetua uma crítica do próprio processo de construção. Esta característica é visível em The Stanley Parable, onde as "estruturas fundamentais da ficção narrativa" são exploradas.

A voz do narrador, que recorre à linguagem literária ${ }^{153}$, bem como os dilemas resultantes da sua ineficácia em acompanhar o rumo da narrativa, produzem um exercício estético. Os textos gerados a cada momento (a narração é acompanhada por legendas) parecem estar na base do sucesso alcançado por The Stanley Parable. Após consultar fóruns e reviews dedicados a este jogo torna-se claro que os jogadores não aderem a este jogo por causa de uma promessa de ação, mas pela forma como esta parábola é veiculada ${ }^{154}$.

Numa das páginas de recensões escritas por jogadores de videojogos intitulada Hardcoregamer, é possível ler a seguinte opinião: "The writing is smart and the narration is excellent, so much so that I usually found myself stopping any time the narrator had something to say just to make sure I didn't miss anything" (Cunningham, 2013). Segundo o autor desta opinião, The Stanley Parable é um jogo de "interatividade limitada", "cujo valor está na descoberta e na experimentação”. The Stanley Parable é constituído por gráficos rudimentares e monótonos e não oferece a mesma intensidade de um jogo de ação. Este jogo não permite ao leitor exibir a sua perícia e técnica. The Stanley Parable é um desafio intelectual que projeta a ilusão de uma narrativa. Esta parábola é constituída por personagens (ainda que fugazes), pelo jogador/protagonista e um narrador. Ela oferece momentos de leitura e audição, mas o seu narrador não consegue veicular uma história. A estrutura de uma narrativa é revelada ao

\footnotetext{
${ }^{153}$ Aqui associa-se a linguagem literária ao uso da terceira pessoa, à prática de descrições longas de uma ação através de um registo formal e a uma escolha cuidada de vocabulário.

${ }^{154}$ Os gráficos também não são um elemento atrativo em The Stanley Parable. Na verdade, a monotonia e a natureza rudimentar dos seus cenários parecem funcionar como um elemento desencorajador.
} 
longo deste jogo. No entanto, o conteúdo dessa narrativa, ou a história, não chega a ser conhecida. Ao edifício da narrativa falta a história. Os seus corredores permanecem vazios e o leitor apenas tem acesso ao que potencialmente poderia ser uma narrativa.

\section{Considerações finais}

Dado o seu carácter híbrido, metaficcional e, porque solicitam um investimento ergódico por parte do leitor, muitas obras parecem oferecer um ambiente inóspito, onde dificilmente uma narrativa poderia prosperar. Esta é vista como dependente de um tecido coerente de eventos e as obras ergódicas podem colocar desafios ao leitor que canalizam a atenção deste para a exploração e configuração do texto. Porém, esses desafios não se limitam ao desenvolvimento destas atividades. Uma obra ergódica é, frequentemente, a origem de enigmas teóricos que envolvem o leitor numa reflexão acerca do ato de leitura, do processo de escrita e acerca da própria literatura. Por vezes, uma história é substituída por (ou surge geminada com) a transmissão de uma ideia ou de um desafio que se refere ao próprio texto. A narrativa, justamente porque é um conceito flexível, mas que contém características que funcionam como elementos distintivos (tais como a existência de personagens, narrador ou sequência de eventos) continua a surgir no discurso dedicado à ficção digital ou ao estudo dos jogos. É justamente esse ato de projetar uma narrativa através dos seus elementos fundamentais que foi captado por este artigo.

A materialidade do texto eletrónico, que se estende do disco rígido até à forma como o significado pode emergir no ecrã, tem uma função primordial na transmissão de uma narrativa. A assimetria entre o plano textónico e escriptónico e a radicação do significado ao nível do processador - e não apenas ao nível do ecrã ou ao nível do que é visualmente percetível pelo leitor - fazem com que a noção de volatilidade do significado ganhe novos contornos. Entre 
o autor e o leitor reside a máquina e, apesar de todo o empenho investido para torná-la cada vez mais neutra e transparente, a sua presença adquire uma expressividade particular em obras de literatura eletrónica. Ainda que o leitor tenha de juntar as peças de um puzzle ou reconstruí-la a partir de sombras e espectros, a narrativa continua a perseverar. Formada entre textões e escritões, ela pode assumir uma forma inusitada quando alcança a superfície do ecrã. Embora ela possa parecer inexistente, a sua presença é frisada ao longo de toda a leitura.

\section{REFERÊNCIAS BIBLIOGRÁFICAS}

AARSETH, E. (1997). Cybertext: Perspectives on Ergodic Literature. Baltimore: The John Hopkins University Press.

ALEXANDER, B. (2011). The New Digital Storytelling: creating narratives with new media. Santa Bárbara, Califórnia: ABC-CLIO, LLC.

ASCOTT, R. (2002). "Is there love in the telematic embrace?" [1990], in Multimedia: from Wagner to virtual reality. Eds. Packer, Randall e Ken Jordan. Nova Iorque: W. W. Norton \& Company Ltd., 333-344.

BARBOSA, P. (1996). "Ângulos e virtualidades do Texto Virtual", in Teoria do Homem Sentado. Porto: Edições Afrontamento. Também disponível em: http://po-ex. net/taxonomia/transtextualidades/metatextualidades-alografas/pedro-barbosa-literatura-teoria-homem-sentado-parte1, consultado a 2 de Setembro de 2015. BARBOSA, P. e TORRES, J. M. (2000). O Motor Textual. Livro Infinito. Porto: Edições Universidade Fernando Pessoa. Também disponível em: http://www.po-ex.net/ taxonomia/transtextualidades/metatextualidades-autografas/pedro-barbosa-o-motor-textual-livro-infinito, consultado a 2 de Setembro de 2015.

BELL, A. (2009). The Possible Worlds of Hypertext Fiction. Londres: PalgraveMacmillan.

BENJAMIN, W. (2003). Das Kunstwerk im Zeitalter seiner technischen Reproduzierbarkeit. Frankfurt am Main: Suhrkamp Verlag. 
BOOTZ, P. (2006). "Digital Poetry: From Cybertext to Programmed Forms”, in Leonardo Electronic Almanac, Vol. 14 Issue 05 - 06, disponível em: http://www.leoalmanac.org/wp-content/uploads/2012/09/04Digital-Poetry-From-Cybertext-to-Programmed-Forms-by-Phillipe-Bootz-Vol-14-No-5-6-September-2006-Leonardo-Electronic-Almanac.pdf, consultado a 2 de Setembro de 2015.

CALlEJA, G. (2011). In-Game: From Immersion to Incorporation. Cambridge, MA: MIT Press.

CUNningham, J. (2013). "Review: The Stanley Parable", in Hardcoregamer, disponível em: http://www.hardcoregamer.com/2013/10/17/review-the-stanley-parable/58895/, consultado a 2 de Setembro de 2015.

ESKELINEN, M. (2012). Cybertext Poetics: The Critical Landscape of New Media Literary Theory. Nova Iorque: Continuum.

FERRET, T. (2008). The Fugue Book, in Electronic Literature Collection, vol. 1, disponível em: http://collection.eliterature.org/2/works/ferret_fugue_book.html, consultado a 2 de Setembro de 2015.

GENETTE, G. (1972). "Discours du récit: essai de méthode”, in Figures III- Collection Poétique. Paris: Éditions du Seuil.

GIBSON, J. (2007). Fiction and the Weave of Life. Oxford: Oxford University Press.

GUMBRECHT, H. U. (2004). Production of Presence: What Meaning Cannot Convey. Stanford: Stanford University Press.

HAYLES, N. K. (2005). My Mother Was a Computer: Digital Subjects and Literary Texts. Chicago: University of Chicago Press.

HAYLES, N. K. (2008). Electronic Literature: New Horizons for the Literary. Notre Dame: University of Notre Dame,

HOWELL, B., Sabrina Small e Jonathan Kemp (2010). exquisite_code (projeto), disponível em: http://exquisite-code.com/.

IRAN, C., Médéric Lulin e Sophie Séguin (2012). La Disparue, in Revue de Littérature Hypermédiatique Bleu Orange, disponível em: http://revuebleuorange.org/ bleuorange/05/iran_lulin_seguin/, consultado a 2 de Setembro de 2015.

ISER, W. (1994). Der Akt des Lesens. München: Wilhelm Fink Verlag.

MANOVICH, L. (2001). The Language of New Media. Cambridge, Massachusetts: MIT Press. 
MARINO, M. C. (2013). “Reading exquisite_code: Critical Code Studies of Literature”, in Comparative Textual Media. Eds. N. Katherine Hayles e Jessica Pressman, 283-309. MORRISSEY, J. (2006). The Jew's Daughter [2000], Electronic Literature Collection, vol. 1, in http://collection.eliterature.org/1/works/morrissey_the_jews_daughter. html, consultado a 31 de Julho de 2014.

ONG, W. J. (1982). Orality and Literacy: the technologizing of the word. Nova Iorque: Methuen \& Co.

RALEY, R. (2001). "Reveal Codes: Hypertext and Performance", in Postmodern Culture, vol. 12, 1, disponível em http://muse.jhu.edu/journals/postmodern_culture/ v012/12.1raley.html, consultado a 2 de Setembro de 2015.

REIS, C. (1997). O Conbecimento da Literatura: Introdução aos Estudos Literários. Coimbra: Livraria Almedina.

RETTBERG, S. (2013). “An Emerging Canon? A Preliminary Analysis of All References to Creative Works in Critical Writing Documented in the ELMCIP”, disponível em (página autor): http://retts.net/documents/Emerging_Canon_S_Rettberg. pdf, consultado a 2 de Setembro de 2015.

RYAN, M. L. (2001). Narrative as Virtual Reality: Immersion and Interactivity in Literature and Digital Media. Baltimore: Johns Hopkins University Press.

RYAN, M. L (2006). Avatars of Story. Minneapolis, MN: University of Minnesota Press. SCHÄFER, J. (2007). "The Gutenberg Galaxy Revis(it)ed", in The Aesthetics of Net Literature: Writing, Reading and Playing in Programmable Media. Eds. Peter Gendolla e Jörgen Schäfer. Bielefeld: Transcript Verlag, pp. 121-160.

SCHÄFER, J. e Peter Gendolla, (2010). "Reading (in) the Net: Aesthetic Experience in Computer-Based Media", in Reading Moving Letters: Digital Literature in Research and Teaching, A Handbook. Eds. Simanowski, Roberto, Jörgen Schäfer e Peter Gendolla. Bielefeld: transcript Verlag, pp. 81-108.

TABBI, J. (2010). "Introduction to Focus: Cognitive Fictions - Cognition against Narrative”, in American Book Review, Vol. 31, 6, Setembro/Outubro, disponível em: http://americanbookreview.org/issueContent.asp?id=190, consultado a 2 de Setembro de 2015.

TABBI, J. (2011). "Cognitive science", in Routledge Companion to Literature and Science. Eds. Clarke, Bruce e Manuela Rossini. Nova Iorque: Routledge, 77-88. 
WAUGH, P. (1996). Metafiction: The Theory and Practice of Self-conscious Fiction. Nova Iorque: Routledge.

WREDEN, D. e William Pugh (2013). The Stanley Parable, disponível em: http://www. stanleyparable.com/, consultado a 2 de Setembro de 2015.

ZUMTHOR, P. (2007). Performance, Recepção e Leitura. São Paulo: Cosac Naify. 